\title{
A FEMALE INTERMEDIATE BETWEEN PAPILIO GLAUCUS AND ITS FORM TURNUS (LEPID.: PAPILIONID $\mathbb{E}$ )

\author{
BY HAROLD O'BYRNE \\ Webster Groves, Missouri
}

It is well known that there are two forms of female in Papilio glaucus Linn., the black type form and the yellow form turnus Linn., and that they are not only sexual forms, but geographical as well. In the southern part of the range of this species, black females are the rule, while in the north, only yellow ones occur; in a considerable region near the middle of its territory, both forms fly together. Missouri is in that intermediate region, though collectors in the neighborhood of St. Louis consider the yellow form somewhat scarce. The males are invariably yellow, and a few closely related species that inhabit the southwestern part of the country and northern Mexico are never black in either sex. To the knowledge of the writer, no breeding has been done in this species with a view toward working out the relations of these forms in the light of genetics. The fact that this condition is linked with sex, and that according to Jordan ${ }^{1}$ there is a rarity of intermediate forms, indicates that this is a Mendelian phenomenon.

Knowing of the rarity of intermediate forms, I was surprised to take at Allenton, Missouri, on August 9, 1931, such a female, having the black color of glaucus, but heavily suffused with yellow on the upper and lower surfaces of both pairs of wings. This has the effect of making the black stripes very noticeable on the upper side, and in this respect the specimen differs markedly from glaucus. This specimen is in no wise comparable to one mentioned by

${ }^{1}$ In Seitz, The Macrolepidoptera of the World. 
Scudder ${ }^{2}$ in which one pair of wings is yellow and the other black. He describes this as a hermaphrodite-really a gynandromorph-while the specimen from Allenton is a normal female with the normal female coloration of both forms and with her abdomen distended with eggs.

Knowing nothing of its antecedents, it is idle to speculate as to the genetic status of this specimen. It probably represents a case of imperfect dominance, but whether this appeared as a mutation is, of course, impossible to say. There is a valuable problem for geneticists.

\section{DENDROIDES CANADENSIS LATREILLE- SYNONYMY}

\section{BY H. S. BARBER}

U. S. National Museum, Washington, D. C.

Those rejecting the adoption in LeConte 1855 of Dendroides canadensis Latreille 1810 with bicolor Newman 1837 in synonymy as the proper name of our commonest Pyrochroid beetle probably did not realize that Latreille's designation (p. 430) of the type species for his monobasic genus erected in the same work (p. 212) connected his new specific name, canadensis, with the diagnosis, thereby making LeConte's use of the name the only proper choice under the International Code of Nomenclature. The misstatements in Lacordaire 1859 evidently led to the synonymy wrongly adopted in Gemminger and Harold 1870, this synonymy being followed by European workers and accepted in Leng 1920. The current synonymy should be reversed and we should go back to the usage reflected in the catalogues by Melsheimer 1853, LeConte 1866, Crotch 1874, and Henshaw 1885, as well as in numerous more local lists prior to 1920 . In the admirably brief but important statement by Miss Payne 1931, recording her six years' observations on larvæ which could not pupate except as stimulated by a particular food, her use of the name

\footnotetext{
${ }^{2}$ Scudder, S. H. The Butterflies of the Eastern United States.
} 

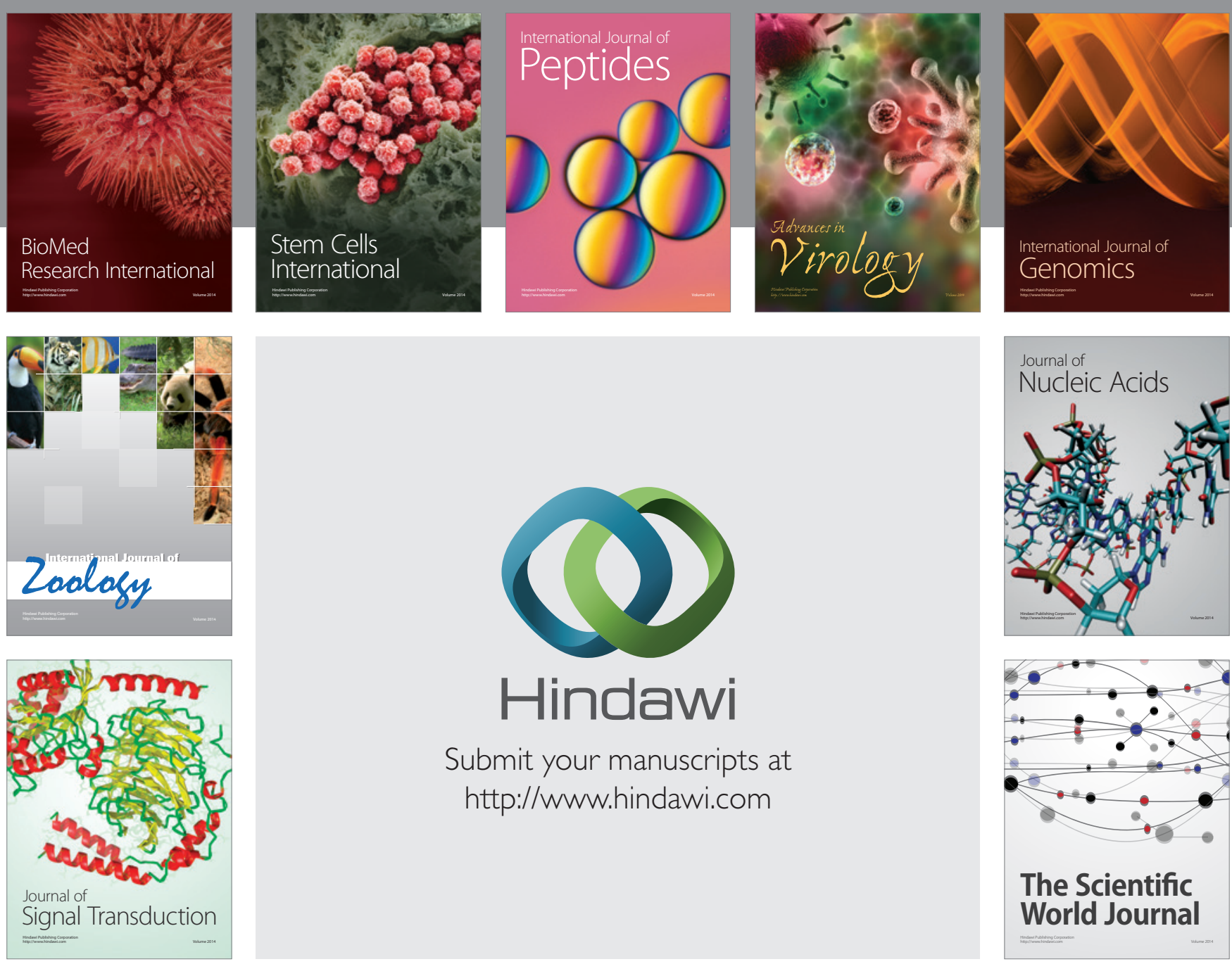

Submit your manuscripts at

http://www.hindawi.com
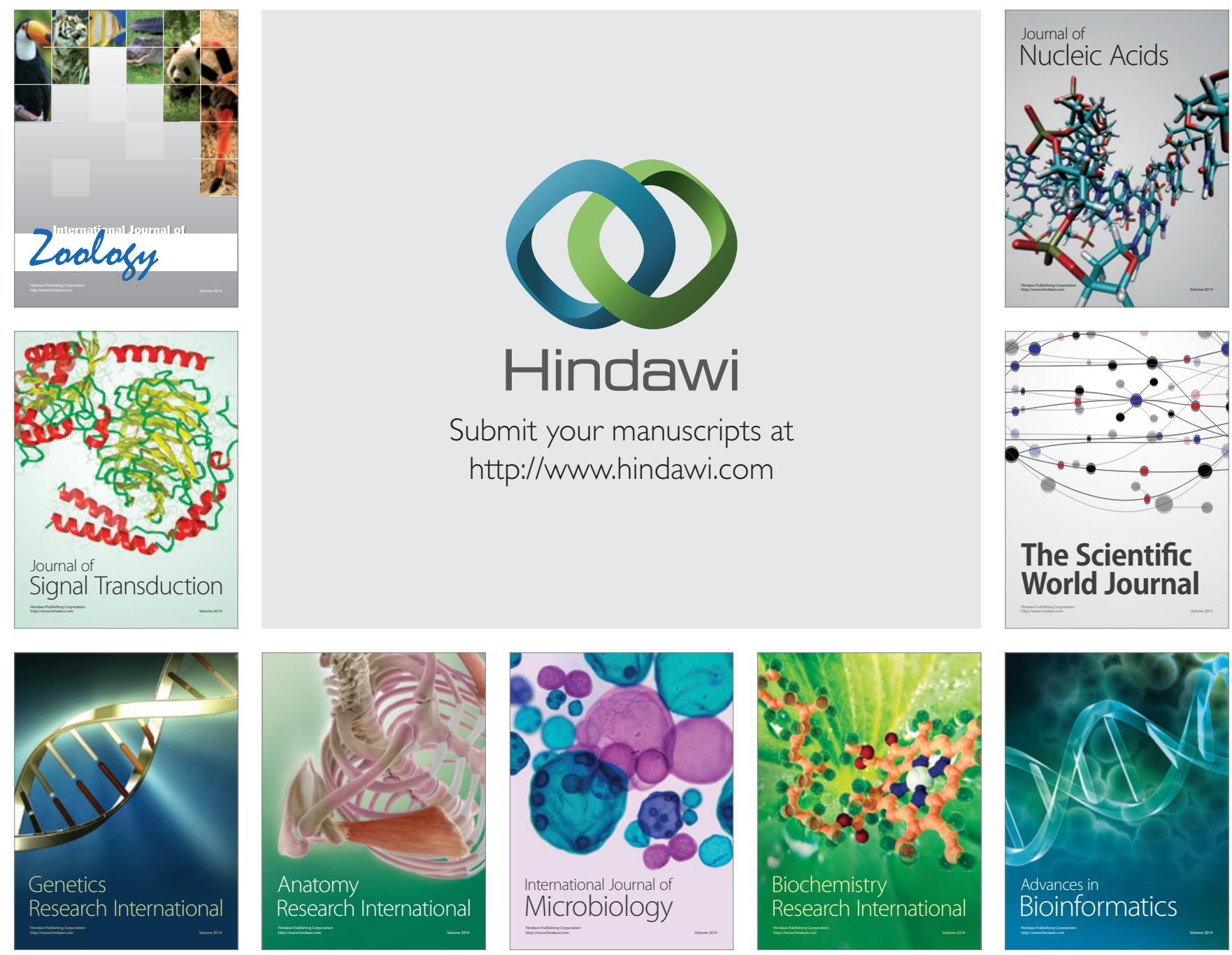

The Scientific World Journal
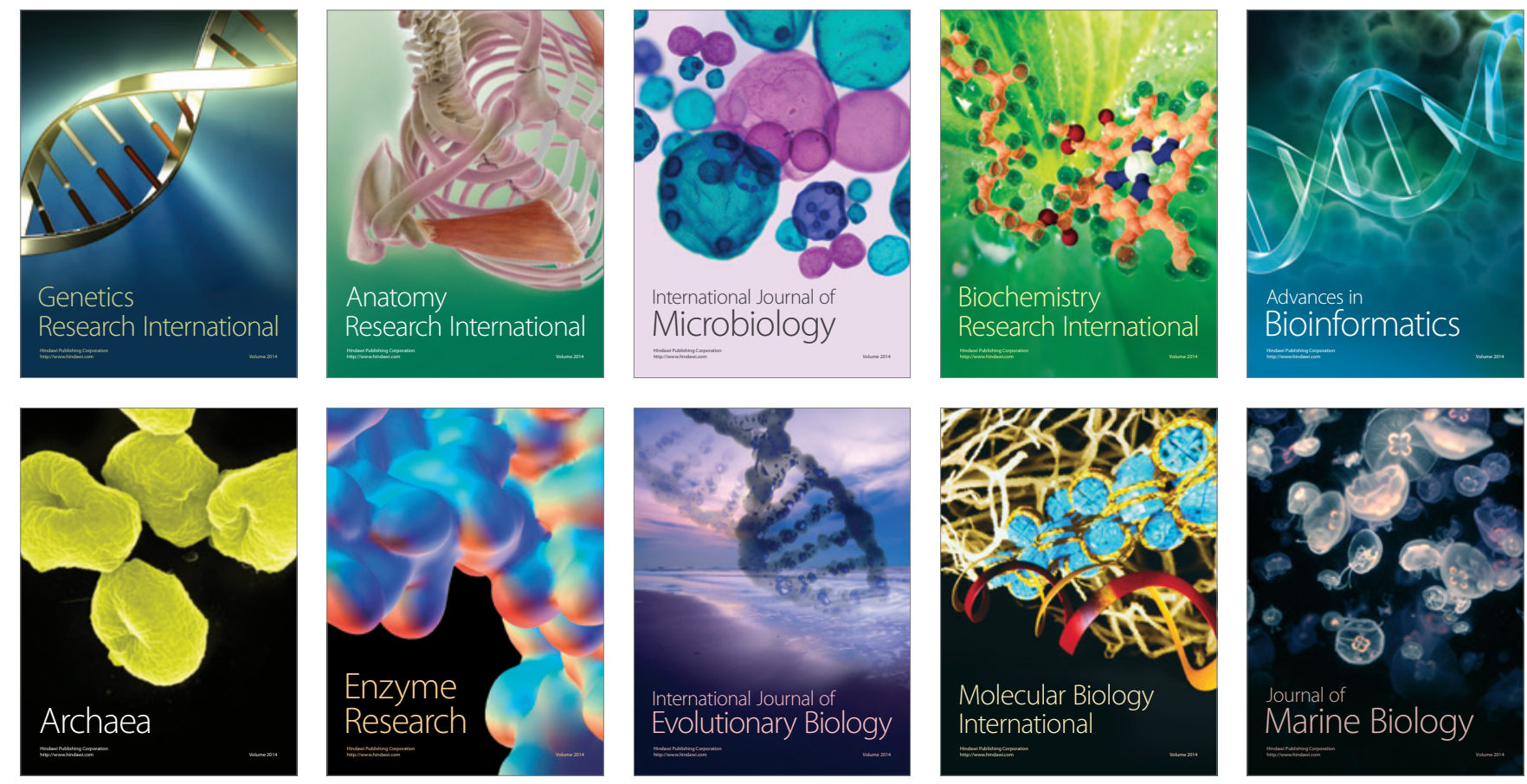